\title{
The Healthy People 2010 smoking prevalence and tobacco control objectives: results from the SimSmoke tobacco control policy simulation model (United States)
}

\author{
David T. Levy ${ }^{1, *}$ Leonid Nikolayev $^{2}$ Elizabeth Mumford $^{3} \&$ Christine Compton ${ }^{2}$ \\ ${ }^{1}$ Senior Scientist, Pacific Institute for Research and Evaluation Professor, University of Baltimore, Maryland, USA; \\ ${ }^{2}$ Computer Programmer, Pacific Institute for Research and Evaluation, University of Baltimore, Maryland, USA; \\ ${ }^{3}$ Associate Research Scientist, Pacific Institute for Research and Evaluation, University of Baltimore, Maryland, USA
}

Received 2 August 2004; accepted in revised form 20 December 2004

Key words: Healthy People 2010, simulation model, smoking, tobacco control policies.

\begin{abstract}
Objectives: Healthy People 2010 (HP2010) set a goal of reducing the adult smoking prevalence to $12 \%$ by 2010 . Smoking prevalence rates do not appear to be declining at or near the rate targeted in the HP2010 goals. The purpose of this paper is to examine the attainability of HP2010 smoking prevalence objectives through the stricter tobacco control policies suggested in HP2010.

Methods: A tested dynamic simulation model of smoking trends, known as SimSmoke, is applied. Smoking prevalence evolves over time through initiation and cessation, behaviors which are in turned influenced by tobacco control policies. We consider the effect of changes in taxes/prices, clean air laws, media campaigns, cessation programs and youth access policies on projected smoking prevalence over the period 2003-2020, focusing on the levels in 2010.

Results: The SimSmoke model projects that the aging of older cohorts and the impact of policies in years prior to 2004 will yield a reduction in smoking rates to $18.4 \%$ by 2010 , which is substantially above the 2010 target of $12 \%$. When policies similar to the HP2010 tobacco control policy objectives are implemented, SimSmoke projects that smoking rates could be reduced to $16.1 \%$. Further reductions might be realized by increasing the tax rate by $\$ 1.00$.

Conclusions: The SimSmoke model suggests that the HP2010 smoking prevalence objective is unlikely to be attained. Although we are unlikely to reach the goals by meeting the HP2010 policy objectives, they could get us much closer to the goal. Emphasis should be placed on meeting the tax, clean air, media/comprehensive campaigns, and cessation treatment objectives.
\end{abstract}

\section{Introduction}

The U.S. Public Health Service issued the Healthy People 2000 (HP2000, [1]) objectives in 1990, which were later revised as the Healthy People 2010 goals (HP2010, [2]). They set objectives not only for reducing the burden of disease and injury, but also for behaviors that contribute to these burdens. Smoking is generally considered the leading preventable cause of death, and has been shown to be responsible for over $85 \%$ of lung cancer deaths as well as a large percentage of deaths from chronic obstructive pulmonary disease and heart disease $[3,4]$.

* Author for correspondence: David T. Levy, Ph.D., Senior Scientist, Pacific Institute for Research and Evaluation Professor, University of Baltimore, 14403 Sylvan Glade Dr., North Potomac, Maryland 20878, USA; Ph: 301-755-2733; Fax: 301-755-2799; E-mail: levy@pire.org
HP2000 originally set a goal of $15 \%$ for adult smoking prevalence [1]. Having declined considerably between 1964 (following the Surgeon General's Report and surrounding publicity) and 1988 [5], adult prevalence leveled off at about $25 \%$ and youth prevalence increased in the early and mid-1990s [5]. Nevertheless, HP2010 set a goal of $12 \%$ for adults in the year 2010 . Although prevalence rates began to decline again in the late 1990s, they do not appear to be declining at or near the rate targeted by HP2010 [6].

Based on past trends, Mendez and Warner [7] have argued that the HP2010 goals are unattainable. Green et al. [8] countered that national trends and trends in states with advanced tobacco control programs indicate that the HP2010 goals are attainable. In particular, states, such as Arizona, California, Massachusetts, and Oregon, have implemented a comprehensive set of 
policies that have reduced smoking to levels that are expected to reach the HP2010 goals.

A set of tobacco control policy objectives, presumably established to help meet the smoking objectives, is outlined in HP2010 and is shown in Table 1. These policies include tax increases, the passage of clean air laws, media campaigns and educational programs, enforcement of youth access laws, and cessation programs. In another paper, we consider the trends in smoking prevalence between 1993 and 2003, and the role of policies in reaching those goals [9]. Except for price increases, modest progress has been made toward reaching the tobacco control policy objectives.

The purpose of this paper is to examine the attainability of the HP2010 smoking prevalence objectives through the stricter tobacco control policies suggested in HP2010. We evaluate the policies at several levels, including those suggested in HP2010. To accomplish that task, we employ a tobacco control policy simulation model known as SimSmoke. The model projects smoking prevalence and estimates the effect of tobacco control policies on that rate.

\section{Methodology}

\section{Basic smoking model}

Discussed elsewhere [10,11], SimSmoke begins with the population of smokers, ex-smokers, and never smokers in the baseline year 1993. The population is distinguished by age and gender. Employing a discrete firstorder Markov process, the population evolves through birth and death rates and the number of smokers, never

Table 1. Healthy people 2010 tobacco control objectives

\begin{tabular}{|c|c|c|c|c|}
\hline \multirow[t]{2}{*}{ Objective } & \multicolumn{3}{|l|}{ Baseline } & \multirow{2}{*}{$\begin{array}{l}\text { Target } \\
2010\end{array}$} \\
\hline & Year & Baseline & 2002 & \\
\hline 27-8a Managed care organization coverage for treatment of nicotine dependency & $1997-98$ & $75 \%$ & - & $100 \%$ \\
\hline $\begin{array}{l}\text { 27-8b Medicaid program coverage for treatment of nicotine dependency } \\
\text { (number of States and D.C.) }\end{array}$ & 1998 & 24 & - & 51 \\
\hline $27-8 c$ Insurance coverage for treatment of nicotine dependency & DNC & $\mathrm{DNC}$ & - & - \\
\hline 27-11 Smoke-free and tobacco-free schools & 1994 & $37 \%$ & - & $100 \%$ \\
\hline 27-12 Worksite policies limiting smoking to ventilated areas & $1998-99$ & $79 \%$ & - & $100 \%$ \\
\hline 27-13a Smoke-free indoor air laws - Private workplaces (number of States and D.C.) & 1998 & 1 & 3 & 51 \\
\hline 27-13b Smoke-free indoor air laws - Public workplaces (number of States and D.C.) & 1998 & 13 & 17 & 51 \\
\hline 27-13c Smoke-free indoor air laws - Restaurants (number of States and D.C.) & 1998 & 3 & 5 & 51 \\
\hline 27-13d Smoke-free indoor air laws - Public transportation (number of States and D.C.) & 1998 & 16 & 18 & 51 \\
\hline 27-13e Smoke-free indoor air laws - Day care centers (number of States and D.C.) & 1998 & 22 & 24 & 51 \\
\hline 27-13f Smoke-free indoor air laws - Retail stores (number of States and D.C.) & 1998 & 4 & 6 & 51 \\
\hline 27-13g Smoke-free indoor air laws - Tribes (number) & DNC & $\mathrm{DNC}$ & - & - \\
\hline $\begin{array}{l}\text { 27-14a Enforcement of illegal tobacco sales to minors laws - Jurisdictions with } \leq 5 \% \\
\text { illegal buy rate among minors (number of States and D.C.) }\end{array}$ & 1998 & 0 & - & 51 \\
\hline 27-15 Retail license suspension for sales to minors (number of States and D.C.) & 1998 & 34 & - & 51 \\
\hline 27-16 Tobacco advertising and promotion targeting adolescents and young adults & $\mathrm{DNC}$ & $\mathrm{DNC}$ & - & - \\
\hline 27-18 Evidence-based tobacco control programs (number of jurisdictions) & $\mathrm{DNC}$ & DNC & - & - \\
\hline 27-19 Preemptive tobacco control laws (number of States and and D.C.) & 1998 & 30 & - & 0 \\
\hline 27-20 Regulation of tobacco products for toxicity & $\mathrm{DNC}$ & DNC & - & - \\
\hline 27-21a Combined federal and average state tax on cigarettes & 1998 & ${ }^{\mathrm{a}} \$ 0.59$ & $\$ 1.00$ & $\$ 2.00$ \\
\hline 27-21b Combined federal and average state tax on spit tobacco & $\mathrm{DNC}$ & DNC & - & - \\
\hline
\end{tabular}

Source: US Dept of Health \& Human Services [2], www.healthypeople.gov/document/HTML/tracking/OD27.htm.

$\mathrm{DNC}=$ Data for specific population are not collected.

Data sources for targets: 03-02 Lung cancer - National Vital Statistics System - Mortality (NVSS-M), CDC, NCHS.

27-01a National Health Interview Survey (NHIS), CDC, NCHS.

27-08a,b Addressing Tobacco in Managed Care Survey, Robert Wood Johnson Foundation.

27-8b Health Policy Tracking Service, National Conference of State Legislators

27-8c Potential: Partnership for Prevention Survey of Employers Sponsored Health Plan

27-11 School Health Policies and Programs Study (SHPPS), CDC, NCCDPHP.

27-12 1999 National Worksite Health Promotion Survey (NWHPS), Association for Worksite Health Promotion (AWHP), ODPHP.

27-13a-f, 27-16-19 State Tobacco Activities Tracking and Evaluation System (STATE), CDC, NCCDPHP

27-14a State Synar Enforcement Reporting, SAMHSA, CSAP.

27-21a The Tax Burden on Tobacco, The Tobacco Institute.

27-21b Potential: OSH. 
smokers, and ex-smokers evolve through initiation, cessation, and relapse rates.

Individuals are classified as never smokers from birth until they initiate smoking or die. Since initiation generally occurs before age 25 [12], initiation occurs until age 25 in SimSmoke. Smokers are defined as individuals who have smoked more than 100 cigarettes in their lifetime and are currently smoking. Ex-smokers are defined as those who have smoked more than 100 cigarettes and are not currently smoking. Cessation and relapse are tracked after age 24. After that age, ex-smokers have been found to have elevated mortality risks [13]. Ex-smokers' relapse rates are distinguished by years since quitting.

Initiation rates at a particular age are measured as the difference between the prevalence of smoking at that age and the prevalence of smoking among individuals one year younger. This measure of initiation net of quitting avoids reliance on separate, relatively unreliable measures of initiation and cessation for those under age 24 and increases the stability of the model.

First-year quit rates are estimated in the cessation module [14, 15]. The module employs a model of the cessation decision and the choice of treatments (no treatment, over-the-counter or prescription pharmaceutical therapy, behavioral therapy, or combinations of the therapies). Based on treatment use and effectiveness, the population cessation rate is predicted over the years 1993-2003. To account for differences in quit rates by age and gender, the one-year quit rates are multiplied by a demographic adjuster variable. Relapse rates for those who successfully quit for at least one year are used to determine the percentage of ex-smokers who again become smokers [3, 13, 16, 17].

Data sources and demographic breakdowns of the data are found in Table 2 and the equations used in the smoking model are found in Appendix A.

\section{Tobacco control policies in SimSmoke and HP2010 policies}

SimSmoke models the effects of price/tax interventions, clean indoor air laws, mass media policies, cessation treatment policies, and strategies to reduce youth access to cigarettes. Actual policies for the US are programmed into the model for the years 1993 through 2003, the most recent year for which data were consistently available. Because the model is for the US and most policies are implemented at the state and local level, unless otherwise indicated, policies are entered as the average of the state (and local in the

Table 2. Data used in SimSmoke

\begin{tabular}{lcc}
\hline Variable & Current source & Current specifications \\
\hline $\begin{array}{l}\text { I. Population model } \\
\text { A. Population }\end{array}$ & 1993 Current Population Survey (CPS) & Breakdowns by age, gender, and racial/ethnic \\
groups & Breakdowns by age and racial/ethnic group \\
B. Fertility rates & U.S. Census Vital Rate Inputs Tables & Breakdowns by age, gender, and racial/ethnic \\
C. Mortality rates & 1993 Multiple Cause-of-Death File & $\begin{array}{l}\text { grotal deaths and by lung cancer, COPD } \\
\text { heart and stroke }\end{array}$
\end{tabular}

A. Baseline smoking rates for current and ex-smokers

\footnotetext{
B. Initiation rates

C. First year cessation rates

D. Relapse rates

E. Relative death risks of smokers and ex-smokers

III. Policy modules

A. Price and taxes

B. Clean air laws

C. Media \& other educational campaigns

D. Youth access
}

Tobacco Use Supplement of the CPS (1992-1993) for age 15+, and 1993 Teenage Attitudes and Practices Survey for <age 15.

Change in smoking rates between contiguous age groups

Calculated from cessation module with adjusters for demographic group based on the CPS U.S. DHHS [13], COMMIT data and other studies Cancer Prevention Study II (see NCI 1997 and U.S. DHHS 2001)

Tobacco Institute, www.bls.gov/cpi/home.htm

CDC and ALA website, National Cancer Institute [18] Different types of laws and their stringency CDC and various state websites, Wakefield and Chaloupka [19], Farrelly et al. (2003)

CDC, SAMHSA Levy et al. [20]
Based on $100+$ cigarettes lifetime and distinction between current and previous smokers. Breakdowns by smoking experience $(<1,1-2,3-$ 5, 6-10, 11-14, 15+ years), age, gender, and racial/ethnic groups.

Breakdowns by age, gender, and racial/ethnic groups.

Breakdowns by age, gender, and racial/ethnic groups.

Breakdowns by age

Breakdowns by age and gender.

Prices and CPI for 1993-2002

Expenditures per capita and audience

Enforcement checks, penalties, community campaigns, self-service and vending machine bans 
case of clean air) policies weighted by the 1993 smoker population. The data sources are presented in Table 2 and are described in detail in Levy and Mumford [21]. The effects of the policies and the strength of empirical evidence for these effects are presented in Table 3 and discussed at more length in Levy et al. [22].

To determine the relationship between policies and smoking rates, each of the policy modules relies on information from the literature as well as "reasonable estimates" developed with the advice of an expert panel. Each policy is expressed in terms of a percentage reduction, $\mathrm{PR}=$ (post-policy rate - initial rate)/initial rate. Unless otherwise indicated, policies have their greatest effect on cessation directly through an additive effect on prevalence [i.e., prevalence* $(1+$ PR $)$ ] spread equally over the first three years that the policy is in effect. The percentage reduction is also applied to the initiation rate as $(1+\mathrm{PR})$ and to the first year cessation rate as $(1-P R)$ throughout the period during which the policy is in effect. When more than one policy is in effect, the percentage reductions are multiplicatively applied, implying that the effect of an additional policy is reduced proportionally to the effect of any previous policy.

\section{Taxes}

The HP2010 set a goal of raising the combined federal and average state tax ("tax rate") on cigarettes to $\$ 2.00$. By 2003, the average level across states had reached $\$ 1.00$.

In the tax module [23], the effect of price/tax changes are modeled as age-specific constant proportional effects on prevalence, initiation, and cessation rates. Based on studies that distinguish by age, the simulation model assigns a prevalence elasticity of -0.6 for individuals below age $18,-0.3$ for those ages $18-24,-0.2$ for those ages $25-34$, and -0.1 for those ages 35 and above. Based on recent evidence [24], the effects have been lowered relative to our earlier work [23].

Table 3. Definition of policies, percentage effect and strength of evidence

\begin{tabular}{|c|c|c|c|}
\hline Policy & Description & Effect $^{\mathrm{a}}$ & Strength of Evidence \\
\hline Tax Policy & $\begin{array}{l}\text { Changes in taxes per pack relative } \\
\text { to the state price for a pack } \\
\text { of cigarettes (branded and generic } \\
\text { cigarettes) }\end{array}$ & $\begin{array}{l}\text { Elasticity }(-0.3)^{\mathrm{c}} \\
-0.6 \text { ages } 15-17-0.3 \text { ages } 18-24 \\
-0.2 \text { ages } 25-34 \\
-0.1 \text { ages } 35 \text { and above }\end{array}$ & High \\
\hline \multicolumn{4}{|l|}{ Clean Air Policies } \\
\hline Total Worksite Ban & $\begin{array}{l}\text { Ban in all indoor worksites in all } \\
\text { areas relative to current private } \\
\text { worksite restrictions }\end{array}$ & $6 \%$ reduction & Medium \\
\hline Total Restaurant Ban & $\begin{array}{l}\text { Ban in all indoor restaurants in } \\
\text { all areas }\end{array}$ & $2 \%$ reduction & Low \\
\hline School and Other Places Bans & $\begin{array}{l}\text { Ban in } 3 \text { of } 4 \text { (government buildings, } \\
\text { retail stores, public transportation } \\
\text { and elevators) and schools }\end{array}$ & $1 \%$ reduction & Low \\
\hline $\begin{array}{l}\text { Highly publicized mass media } \\
\text { campaign }\end{array}$ & $\begin{array}{l}\text { Per capita expenditures of } \$ 3.50 \text { (on } \\
\text { TV and other media with sound social } \\
\text { marketing approach), and with } \\
\text { publicity from other policies }\end{array}$ & $6 \%$ reduction & Medium \\
\hline Cessation Treatment Policy & $\begin{array}{l}\text { Mandated complete financial } \\
\text { coverage of pharmacotherapy and } \\
\text { behavioral treatments with flexibility } \\
\text { to choose, and pro-active physician } \\
\text { involvement }\end{array}$ & $1-2 \%{ }^{\mathrm{d}}$ & Low \\
\hline $\begin{array}{l}\text { Strongly enforced \& publicized } \\
\text { youth access restrictions }\end{array}$ & $\begin{array}{l}\text { Compliance checks are conducted } \\
4 \text { times per year per outlet, } \\
\text { when penalties are potent and } \\
\text { enforced, and with community } \\
\text { mobilization }\end{array}$ & $\begin{array}{l}25 \% \text { reduction } \\
30 \%<\text { age } 16 \\
20 \% \text { ages } 16-17\end{array}$ & Medium/Low \\
\hline
\end{tabular}

\footnotetext{
a The percentage reductions are applied to the prevalence, cessation rates and initiation rates, unless otherwise indicated (further discussion can be found in articles cited in text). Prevalence effects (direct reductions in prevalence) are distributed over a 2-3 year period).

b Evaluated in terms of strong, medium and week. (See Levy, Gitchell et al. 2004 for further discussion).

c Elasticity measures the percentage effect relative to the percentage change in price.

${ }^{\mathrm{d}}$ Cessation treatment policies affect only the first cessation rate (a $28 \%$ increase) which translates into prevalence increasing from $1.4 \%$ in the first two years to $5 \%$ after 20 years (Levy and Friend 2002).
} 
Through 2002, prices are averaged over states with weights based on tobacco sales, and are adjusted for inflation. After 2002, prices are adjusted to change by the amount of change in the average state plus federal tax on cigarettes and corrected for a 3\% rate of inflation. HP2010 set a goal of raising the tax rate from its baseline year level of $\$ 0.59$ in 1998 to $\$ 2.00$ in 2010. By January 2002 , the tax rate was $\$ 0.80$, increased to $\$ 1.00$ by 2003 , and reached $\$ 1.13$ ( $\$ 0.74$ state $\$ 0.39$ federal) by 2004 (tobaccofreekids.org/research/factsheets/pdf/0212.pdf, visited 06/07/04).

\section{Clean air laws}

HP2010 sets goals for seven types of smoke-free laws for the 50 states and Washington, DC: private workplaces, public workplaces, restaurants, transportation, day care centers, retail stores, and tribes. The clean air policy module in SimSmoke examines the effect of four types of laws: work site, restaurant, school, and other public places [25]. Unlike the HP2010 goals, SimSmoke does not distinguish public from private worksites nor public transportation and retail stores within "other public places." Evidence on clean air laws for tribal areas and daycare centers is lacking and their effect on adult smoking is expected to be small.

SimSmoke projects a maximum $11 \%$ reduction in prevalence rates with all policies fully implemented and with strong enforcement and media publicity [25]. Work site laws have the largest maximum effect, $7 \%$, with restaurant laws producing a $2 \%$ effect, and laws covering schools and other places each having about a $1 \%$ effect. The effects for each law in future years are reduced to the extent that states already have laws in effect (including partial bans), and the effect of work site laws incorporates the effect of labor participation and of private work site restrictions that have already been implemented [25]. Based on differences in labor participation rates and in the effect on workers who smoke, females experience $80 \%$ of the effect compared to males, and effects are highest between ages 26 and 39 .

By January 2004, eight states adopted smoke-free restaurant laws (California, Connecticut, Delaware, Florida, Maine, New York, Utah and Vermont) and seven states (California, Delaware, Florida, Maryland, New York, South Dakota and Washington) adopted stricter work laws that required separately ventilated areas for smokers or no smoking.

\section{Mass media}

HP2010 goals do not explicitly state a goal for media campaigns but do include evidence-based tobacco control programs. Evidence-based tobacco control programs are described as "comprehensive tobacco control programs," such as those in Arizona, California and Massachusetts. "(C)ounter-advertising (media) campaigns to deglamorize and denormalize tobacco use, especially among young people, with unequivocal messages about the negative effects of tobacco use on health, performance, and appearance" are viewed as an "integral part" [2] of comprehensive programs.

The mass media campaign module in SimSmoke focuses on media campaigns in the context of comprehensive tobacco control campaigns, such as state and local programs, clean air initiatives and other educational programs. The effects are based largely on campaigns in California and Massachusetts [26]. Media expenditures must be high enough for messages to reach smokers a sufficient number of times, but after a threshold additional expenditures show diminishing returns. The module distinguishes campaigns directed at all smokers and those directed at youth. The latter includes school education programs as part of the broader campaigns. Educational programs are not considered separately because of the lack of consistent findings of long-term effectiveness in reducing smoking rates [22].

When part of a comprehensive tobacco control program, SimSmoke projects that mass media policy directed at all smokers may yield up to a 7\% reduction in smoking rates over the entire population when combined with other policies. Youth-oriented campaigns are distinguished from those directed at all smokers. Their effects peak at a $6.5 \%$ reduction in youth prevalence, but the effects are minimal in the general population.

To incorporate the effect of past media campaigns, state per capita expenditures between 1993 and 2003 were used to calculate the implied annual reductions in smoking rates by state. The annual reductions were then weighted by the number of smokers in a state, with separate estimates for campaigns directed at youth and all ages. Between 1993 and 1999, Massachusetts, followed by Utah, Arizona, Florida and Oregon implemented campaigns, and California had a media campaign prior to 1993. Since 1999, Alaska, Maine, Idaho, Indiana, Maryland, Minnesota, Mississippi, New York, New Jersey and Vermont have added campaigns, but many were primarily directed at youth, and some were conducted at a low level. Since January 2002, Arkansas, Hawaii, and Delaware have implemented campaigns, but many states (including California, Colorado, Massachusetts, Minnesota, New Jersey and Oregon) reduced campaign expenditures due to state fiscal constraints (Tobaccofreekids.org/reports/settlements/2004/trends.pdf and slati.lungusa.org/reports/ SLATI2004MidTermReport.pdf, both visited 06/07/04). 
Due to difficulties in obtaining measures in recent years, media campaigns are only considered through 2002, but media expenditures since then have decreased in some states.

\section{Cessation treatment policies}

HP2010 sets the policy objective of all states providing Medicaid coverage for treatment of nicotine dependency, but does not specifically consider state-mandated coverage for other payers. Instead, HP2010 sets separate goals of complete coverage by managed care and by insurers. Under access to quality health care services, a goal is set that health care providers routinely advise and assist smokers to quit (objective 1-3c).

The cessation policy module in SimSmoke considers the effects of a policy of mandated brief interventions delivered by health care providers to encourage patients to quit smoking and the full financial coverage of cessation treatments, with the smoker having the flexibility to choose from the array of cessation treatment options [14,15]. Unlike other policy modules, cessation policies only affect first year quit rates. They increase the quit rate by $28 \%$, which translates into smoking prevalence increasing from $1.4 \%$ in the first two years to $5 \%$ after 20 years [15].

The predictions of the average population quit rate over the years 1993 through 2000 are based on treatment usage rates and compare well to actual rates [14]. From 2004 forward, the module takes into account the level of treatment coverage and health care involvement in 2003. Medicaid coverage for treatment of nicotine dependence began in 1994 in Rhode Island. By 2003 [27], 36 Medicaid programs covered some counseling or medication for all Medicaid recipients, but only New Jersey and Oregon offered comprehensive coverage. Measures of insurance coverage by private payers are more limited [14]. A study of managed care organizations [28] found that $59 \%$ of plans had some type of pharmacotherapy coverage and $86 \%$ had some kind of behavioral coverage, but a study of employer coverage (www.cdc.gov/tobacco/educational_materials/cessation/ page1.html) found that only $24 \%$ of employers provided any type of cessation treatment coverage.

\section{Youth access}

HP2010 set an objective of reducing to $5 \%$ the proportion of stores that sell cigarettes to youth below the age of 18 . HP2010 does not specify particular policies except the licensing of retail establishments with license suspension for sales to minors.

The youth access module in SimSmoke considers the effect of restrictions on self-service and vending machines, and three components of retail compliance: compliance checks, penalties, and merchant awareness/ community mobilization. The module incorporates interactive effects between the policy components and diminishing returns to each of them. As retail sales to youth are reduced in the module, youth switch to nonretail sources such as theft, older peers and parents. This substitution limits the effect of youth access policies to a maximum reduction in youth smoking prevalence of $30 \%$ for 10 to 15 -year-olds and $20 \%$ for 16 and 17 -yearolds $[20,29]$.

The youth access module considers the change in laws banning vending machines and self-service displays, and the extent of compliance checks, penalties, and merchant awareness/community mobilization enforcement programs in individual states over the period 1993-2003 (Levy et al. 2001). The model then derives the extent of retail compliance. The model projects that average state compliance increased from about 30\% in 1993 to about $75 \%$ in 2003.

\section{The effect of tobacco control policies in reaching HP2010 goals}

The smoking prevalence rates for adults (age 18 and above) in the years 1993-2003 predicted by SimSmoke are close to the levels as measured by National Health Interview Survey (NHIS) data [30], that is used in assessing HP2010 smoking rate objectives. In addition, the predicted smoking prevalence rate in the year 2003 is within $2 \%$ of the preliminary estimate from NHIS data. Thereby, the validity of the model has been assessed and confirmed as a sound basis for projections from the year 2003.

We first assume that policies remain constant at the year 2003 levels, which we call the status quo scenario, and examine the future trends in smoking prevalence. We then consider the effect of implementing different policies on smoking prevalence from the year 2005, the earliest year from which we expect policies could be implemented. We focus on the policies in SimSmoke, which correspond to the objectives prescribed by HP2010. We examine the effect of each policy individually by implementing the policy at a specific level for the year 2005 and holding that level constant in all future years. After individually examining policies, we then enter a combination of the policies to project the impact of a "comprehensive strategy." Comparisons are made to the status quo policy.

We consider the effect of the various scenarios through 2010 to determine their impact relative to HP2010 objectives, and consider longer time frames to gauge the more long-term feasibility of reaching 
smoking prevalence goals. We separately consider the effect of tax and clean air policies implemented between January 2003 and January 2004; data limitations impede our ability to consider other policies over that year.

\section{Results}

We present the effect of varying levels of tobacco control policies in isolation and together through a comprehensive tobacco control strategy. The estimates of smoking prevalence under the status quo (Model 1) and varying policy scenarios (Models 2-7) are shown for the adult (18 year and above) population in Table 4.

\section{The Status Quo Scenario}

If tobacco control policies remain unchanged from their 2003 levels, as in the status quo scenario (Model 1), adult smoking prevalence is projected to decline from the 2003 level of $21.3 \%$ to the 2010 level of $19.4 \%$. This absolute reduction of 1.9 percentage points represents an $8.9 \%$ decline relative to the 2003 level. Kept at 2003 policy levels, smoking rates are projected to fall to $17.7 \%$ by 2020. At least some of the reduction in smoking prevalence is explained by stricter public policies implemented prior to 2003, including the increase in prices since 1998, more stringent smoking restrictions in work and public places, and better information about the effects of smoking [31].

We also examined the effect of policies implemented between January 2003 and January 2004. We first examined the increase in the average tax rate from $\$ 1.00$ in 2003 to $\$ 1.13$ in 2004 (not shown in Table). From 2003, this increase is projected to result in an absolute decline of $2.5 \%$ in adult smoking prevalence by 2010 to $18.8 \%$, which is $1.7 \%$ lower in relative terms than the 2003 status quo level. SimSmoke projects that the stricter clean air laws implemented in Connecticut, Florida, Maine and New York between January 2003 and January 2004 would reduce the smoking prevalence by $0.35 \%$ relative to the status quo, of which $0.15 \%$ is due to work site laws, and $0.2 \%$ is due to restaurant laws. As a result of stricter clean air laws and tax increases between 2003 and 2004, the smoking rate is projected to be $18.5 \%$ in 2010 , which is $7 \%$ below the status quo level of $19.4 \%$.

\section{Taxes}

Of the tobacco control policies, SimSmoke attributes the most pronounced effect on smoking prevalence trends between 1993 and 2003 to taxes [9]. However, the same absolute increase in taxes or price has a smaller percentage effect at the higher prices found in 2004 than in earlier years. An increase in the average tax rate from the 2004 level of $\$ 1.13$ to $\$ 2.00$ (Model

Table 4. Projected adult smoking prevalence from 2003 to 2010, 2015 and 2020 under policy scenarios corresponding to HP2010 policy objectives

\begin{tabular}{|c|c|c|c|c|c|c|c|}
\hline Model Year & $\begin{array}{l}(1) \\
\text { Status quo } \\
\text { in } 2003(\%)\end{array}$ & $\begin{array}{l}(2) \\
\text { Tax of } \\
\$ 1.13 \text { in } 2004 \\
\text { and } \$ 2 \\
\text { in } 2005+(\%)\end{array}$ & $\begin{array}{l}(3) \\
\text { Clean air laws } \\
\text { w/ enforce. } \\
\text { and } \\
\text { publicity }^{\mathrm{a}}(\%)\end{array}$ & $\begin{array}{l}(4) \\
\text { Media } \\
\text { cam-paign }{ }^{\text {a }}(\%)\end{array}$ & $\begin{array}{l}(5) \\
\text { Cessation } \\
\text { coverage } \\
\text { and physician } \\
\text { interv. }^{\mathrm{a}}(\%)\end{array}$ & $\begin{array}{l}\text { (6) } \\
\text { Youth } \\
\text { access }^{\mathrm{a}}(\%)\end{array}$ & $\begin{array}{l}\text { (7) } \\
\text { All } \\
\text { policies }^{\text {a }}(\%)\end{array}$ \\
\hline 2003 & 21.3 & 21.3 & 21.3 & 21.3 & 21.3 & 21.3 & 21.3 \\
\hline 2004 & 20.9 & 20.8 & 20.9 & 20.9 & 20.9 & 20.9 & 20.9 \\
\hline 2005 & 20.6 & 20.3 & 20.2 & 20.1 & 20.6 & 20.6 & 19.4 \\
\hline 2010 & 19.4 & 18.7 & 18.4 & 18.3 & 19.0 & 19.3 & 16.1 \\
\hline $\begin{array}{l}\text { Abs change } \\
2003-2010\end{array}$ & -1.9 & -2.6 & -2.9 & -3.0 & -2.3 & -2.0 & -5.3 \\
\hline $\begin{array}{l}\% \text { change } \\
2003-2010\end{array}$ & -8.8 & -12.3 & -13.6 & -14.2 & -10.9 & -9.3 & -24.7 \\
\hline $\begin{array}{l}\% \text { change from } \\
2010 \text { status quo }^{b}\end{array}$ & & -4.0 & -5.2 & -5.9 & -2.3 & -0.6 & -17.4 \\
\hline $\begin{array}{l}2015 \\
\% \text { change from } \\
2015 \text { status quo }^{b}\end{array}$ & 18.5 & $\begin{array}{r}17.7 \\
-4.4\end{array}$ & $\begin{array}{r}17.5 \\
-5.4\end{array}$ & $\begin{array}{r}17.3 \\
-6.3\end{array}$ & $\begin{array}{r}17.8 \\
-3.7\end{array}$ & $\begin{array}{r}18.2 \\
-1.3\end{array}$ & $\begin{array}{r}14.7 \\
-20.2\end{array}$ \\
\hline $\begin{array}{l}2020 \\
\% \text { change from } \\
2020 \text { status quo }\end{array}$ & 17.7 & $\begin{array}{r}16.8 \\
-4.8\end{array}$ & $\begin{array}{l}16.7 \\
-5.8\end{array}$ & $\begin{array}{r}16.5 \\
-7.1\end{array}$ & $\begin{array}{r}16.9 \\
-5.6\end{array}$ & $\begin{array}{r}17.3 \\
-4.4\end{array}$ & $\begin{array}{r}13.7 \\
-25.3\end{array}$ \\
\hline
\end{tabular}

Source: from SimSmoke model

a Policies are implemented and maintained from year 2005 forward.

b Percent changes calculated relative to the status quo rate at (Policy rate-status quo rate)/status quo rate. 
2 ) is projected to result in an absolute decline of $2.6 \%$ in adult smoking prevalence between 2003 and 2010, which represents a $12.2 \%$ relative drop. This drop is $4.0 \%$ greater than the status quo level in relative terms, which increases to $4.4 \%$ by 2015 and $4.8 \%$ by 2010. The growth in effect over time is primarily because youth are more responsive to price increases than adults. However, some of the effect on smoking prevalence dissipates over time if the per unit taxes are not increased with the rate of inflation [23].

\section{Clean air policies}

Clean air policies have a similar effect on smoking prevalence compared to tax policies. Model 3 shows the effects derived from implementing a total smoking ban in workplaces, restaurants and public places supported by both publicity and enforcement of the ban. By 2010, these policies lead to a $2.9 \%$ absolute and a $13.6 \%$ relative drop in the smoking rate from its 2003 level. The declines represent a 5.2\% reduction relative to the status quo scenario, which increases to a $5.8 \%$ drop by 2020 , primarily due to higher cessation rates. Over the same period, a policy with a ban limited to restaurants yields relative declines in adult prevalence of less than $2.1 \%$. A clean air policy limited to a workplace ban leads to a $2.5 \%$ drop, and the remaining effect is attributed to bans in schools and "other places."

Clean air policies are projected to have a smaller impact on youth smoking, but have a relatively larger impact on males, especially between the ages of 26 and 39 . There would also be greater effects if some states did not already have clean air laws and many firms did not already have strict work site bans.

\section{Mass media and educational policies}

We examine a comprehensive media campaign directed at all smokers (i.e., not targeted to a specific population, such as youth) with expenditures of $\$ 3.50$ per capita (Model 4) and maintained over time. The absolute decline of $3.3 \%$ in adult smoking after seven years translates to a $15.1 \%$ drop from its 2003 level and a $5.9 \%$ drop relative to the status quo. The effect increases to a $7.1 \%$ reduction relative to the status quo by 2020 .

\section{Cessation policies}

A policy of mandated brief interventions delivered by health care providers along with full financial coverage of cessation treatments have smaller effects in the earlier years of the projection, but their impact grows over time through increased cessation rates [14]. The combined cessation policies (Model 5) are projected to reduce adult smoking prevalence by an absolute value of $2.6 \%$ by 2010 , or, in other words, a $2.3 \%$ relative improvement over the status quo scenario. This effect grows to $5.6 \%$ reduction by 2020 .

\section{Youth access policies}

Assuming strict control of youth access (Model 6; bans on access to self-service and vending machines in addition to strict retail compliance checks, penalties for noncompliance and a high level of publicity), youth smoking is projected to decline by $25 \%$ relative to the status quo conditions after two years and to stay at that level. Not surprisingly, adult smoking rates (of which youth are only included in later years) decline by a small amount $(2.0 \%)$ relative to the status quo by 2010 , with a greater decline of $4.4 \%$ by 2020 as a large portion of youth affected by the policies age.

\section{A comprehensive set of policies}

Model 7 projects for a combination of policies (Models $2,3,4$, and 6) representing a tax increase to reach a $\$ 2.00$ tax rate; worksite, restaurant, and public place smoking bans with publicity and enforcement; a high intensity media campaign; comprehensive cessation policies; and strict youth access policies. The smoking rate is projected to fall to $16.1 \%$ by 2010 , which is $17.4 \%$ below the status quo level of $19.4 \%$ in relative terms. Maintaining this policy is projected to reduce the smoking rate to $13.7 \%$ by 2020 , which is $25.3 \%$ below the status quo.

Figures 1 and 2 show the percentage contributions of each of the policies projected by the year 2010 and 2020, respectively. Media campaigns, clean air laws and taxes play the largest roles in 2010, but cessation treatment and youth access policies play a greater role by 2020 . Some policies have a larger impact on adult smoking prevalence and others on youth prevalence. Youth smoking prevalence exhibits an even larger reduction of $38 \%$ by 2010 than the $25.3 \%$ reduction for adults. The effects of a comprehensive policy strategy are shown as the original SimSmoke screen in Figure 3.

\section{Conclusions}

Consistent with the simulation model of Mendez and Warner [7], the SimSmoke model suggests that the HP2010 smoking objectives are unlikely to be attained. 


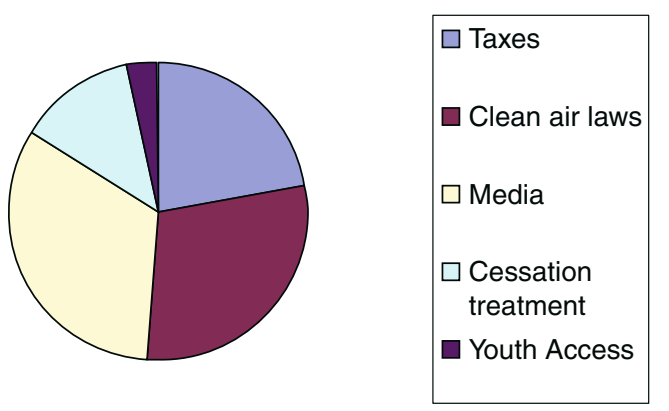

Fig. 1. Percent of smoking rate reduction attributable to each policy 2010.
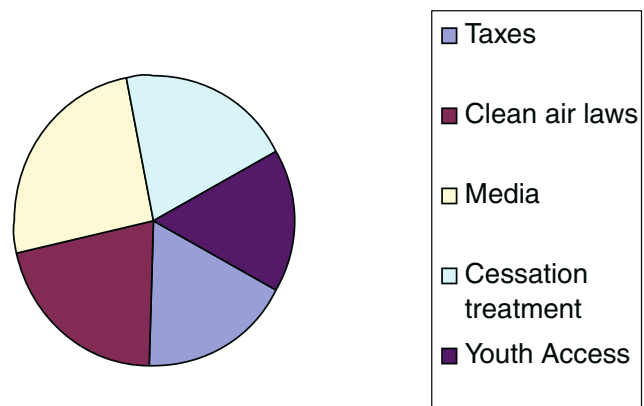

Fig. 2. Percent of smoking rate reduction attributable to each policy by 2020 .

The model projects a reduction in smoking rates to $18.4 \%$ by 2010 , due to the aging of older cohorts and the impetus from policies in years through 2004. This rate is substantially above the 2010 target of $12 \%$. SimSmoke projects, however, that smoking rates could be reduced to $16.1 \%$ with a set of policies similar to the HP2010 objectives for tobacco control policies, and the HP2010 smoking prevalence goal could be met in 2020. The cumulative impact of the comprehensive set of policies over a 15 -year period provides strong encouragement for implementing the HP2010 policy objectives as early as possible.

The tobacco control objectives in HP2010 provide an important guide for policy makers in developing effective tobacco control strategies. However, the various policy goals differ in terms of the extent to which they have been achieved across states, how well they are defined, and the strength of evidence for their effectiveness.

Tax changes are relatively well defined and easily measurable, and there is strong evidence that tax policy is effective at reducing smoking rates and is especially effective in reducing youth smoking prevalence [22, 23]. With the $\$ 0.39$ federal tax, New Jersey, Rhode Island and the city of New York surpassed and 16 states and Washington, DC were within at least $70 \%$ of the HP2010 goal of $\$ 2.00$. While many states have shown much progress toward reaching the HP2010 tax goals, there is still considerable variation in state taxes. As of January 2004, cigarette taxes ranged from a high of $\$ 2.05$ per pack in New Jersey to a low of 2.5 cents per pack in Virginia. It will be especially important for states with the lowest tax rates to increase their rates, both because the same size price increase will yield larger percentage decreases in smoking prevalence and because more uniform taxes across states will reduce illegal, interstate purchases. As taxes increase, internet purchases may also become more important. Laws against internet purchases, such as those in New York and several other states, will need to be passed by other states and actively enforced.

The model calculated the effect of taxes using the 2004 average tax across states, and did not take into account the non-linear relationship that results from variation across states in the initial price nor the extent of tax changes necessary to reach the HP2010 goal. When we considered such variations in a separate model, we found that the effects increased by $10 \%$, implying that smoking prevalence may be reduced by an additional $0.4 \%$ from $16.1 \%$ to $15.7 \%$ in 2010 . In addition, prospects for future tax increases are likely to be strong with the current fiscal crises faced by states. Based on the strength of the evidence, it might be argued that taxes should be increased beyond the HP2010 objective. If an additional tax of $\$ 0.50$ beyond the $\$ 2.00$ level is implemented in conjunction with policies meeting the HP2010 goals for other policies, the smoking prevalence is projected to be reduced in absolute by an additional $0.3 \%$.

Another "low cost" policy is the passage of laws to restrict smoking in public places and worksites. As indicated in Table 3, evidence of the effect of worksite restrictions on quantity smoked is strong, but the strength of evidence regarding the effect of clean air laws on smoking prevalence generally is less strong [22, 32]. In recent years, several states have implemented stronger clean air laws, but most states still have not implemented laws in the important areas of worksites and restaurants. SimSmoke takes into account the effects of private worksite restrictions currently in place and enhanced publicity and enforcement. Private worksite restrictions have increased in recent years in all states, with the greatest gains in those states with lower smoking rates [33]. Enforcement of these bans and the implementation of new worksite and home bans may be enhanced through media campaigns that publicize the health effects of second hand smoke.

Our estimates of the effect of media campaigns assume that they have been implemented as part of broader tobacco control programs. While studies have shown 


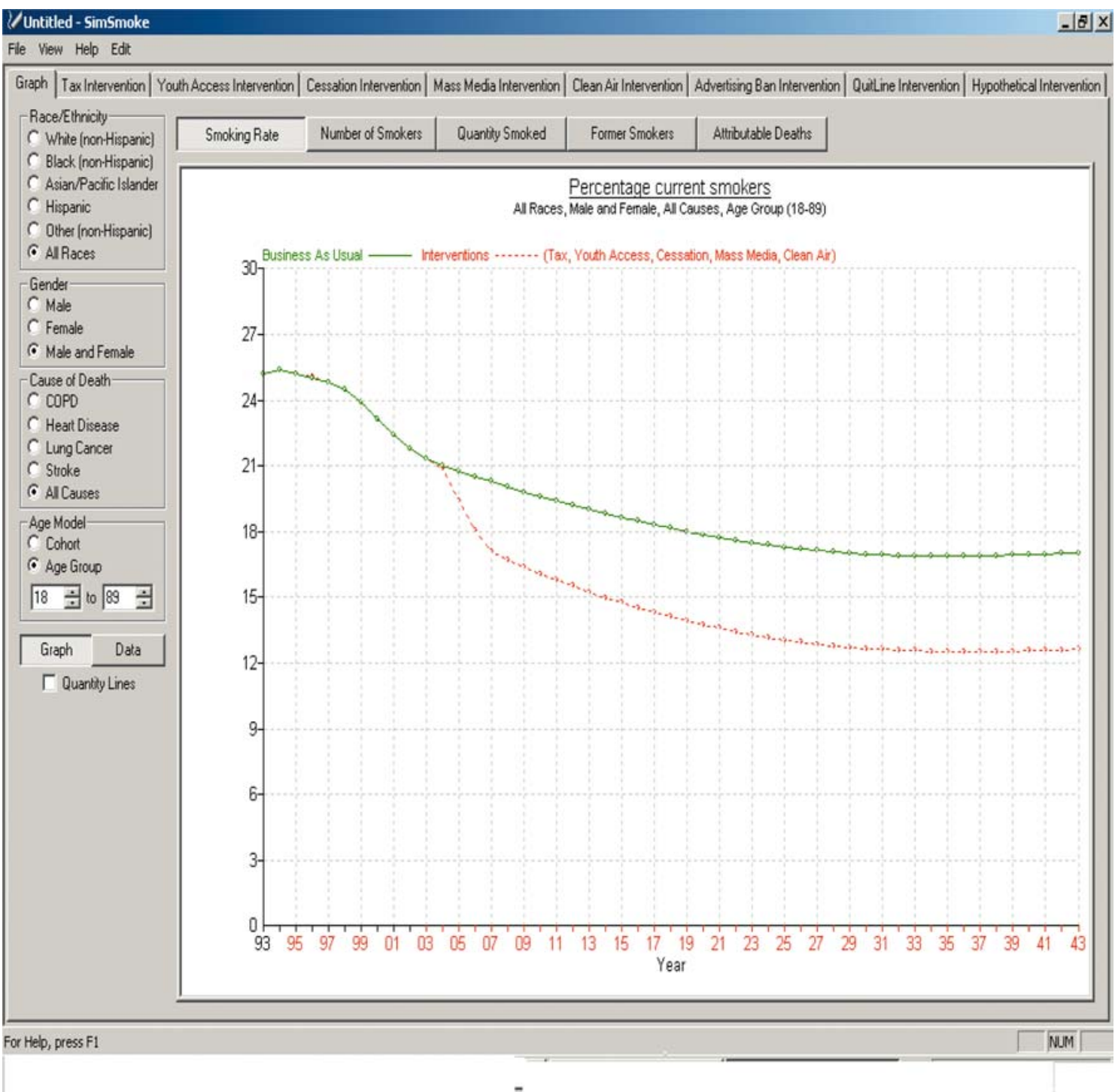

Fig. 3. SimSmoke presentation with status quo and HP2010 policies.

states with media campaigns as part of broader tobacco control programs have shown gains, the specific role of media campaigns is less clear $[32,34]$. In addition, measures of the extent of these programs at the state and local level are not readily available, and many states have recently cut back on their expenditures.

The HP2010 goals focus on Medicaid laws regarding treatment and insurance coverage. Evidence of the effectiveness of treatment is strong, but evidence of the effect of specific public policies is based on few studies $[22,32]$. Using the same base SimSmoke model as in this study, Levy and Friend [15] found that the effects on cessation rates could vary from one-half to three times the current projection depending on assumptions about the parameters of the model, and that the effects would also vary considerably depending on the type of treatments covered and restrictions on treatment. Further, some recent evidence indicates that the effectiveness of pharmacotherapy may be declining [35, 36], but new pharmacotherapies and other forms of therapy targeted to specific populations may improve treatment effectiveness.

There is some evidence of a modest improvement in the provision of cessation treatment services in the last ten years, but more attention is needed to develop policy-related measures. While not specifically considered in the model or the HP2010 goals, telephone quitlines are becoming widespread in the US and 
provide a potentially effective way to increase cessation rates. However, studies for the US generally indicate that less than $2 \%$ of smokers call quitlines even in the first year of operation [22, 32], suggesting modest effects on smoking prevalence before the year 2010. If, however, cessation treatment is provided at no cost to callers and quitlines are part of a broader, widely publicized tobacco control campaign, their reach as well as effectiveness might be increased.

Evidence on the effectiveness of youth access policies is weak, with mixed effects across studies [22, 32]. Attention needs to be focused on developing standardized measures of retail compliance and identifying the components of successful youth policy. Policy effectiveness is also likely to depend on strong adult programs (especially directed at those ages 18-20), since adults provide important sources of cigarettes to youth [20]. Although the effects of youth access policy are subject to considerable uncertainty, they are unlikely to much affect the attainability of reaching HP2010 goals, because reductions in adult smoking rates are mostly realized in future years [10].

Research has shown that the most effective tobacco control campaigns use a comprehensive set of policy measures [31, 37]. Our modeling of the effect of media campaigns and youth access policies incorporates synergies that arise from the publicity that surrounds other policies. We have also built certain synergies into the model between clean air laws and other policies (through enforcement and publicity), and between youth access laws and other policies. We have, however, otherwise assumed that the effect of different policies is multiplicative, which implies that the absolute reduction in prevalence due to a particular policy is less when other policies are implemented. Research has generally not been able to distinguish the interactive effects of different policies, especially in regard to how they affect different demographic groups [22]. The link between youth smoking and that of older peers and parents as affected by different policies is of particular interest.

While we have examined the smoking prevalence of all adults in the population, policies might be improved by targeting specific demographic groups. Increasing the likelihood of quitting [38] in the 18 to 24-year-old age group, when smoking rates often become established, merits particular attention. While smoking rates by most accounts have fallen quite substantially for children younger than 18 between 1997 and 2002, smoking rates for those ages 18 to 24 have stayed flat [9]. Media campaigns and cessation programs should target this age group. Strict clean air laws, especially at colleges and workplaces, might also discourage smoking at these ages.

We have focused on smoking prevalence, and have not considered the role of quantity smoked. During the 1990s, the quantity smoked by smokers declined [5]. These declines may have fueled the apparently larger reductions in prevalence in recent years by quantity reductions, as well as other harm reduction strategies, may yield health gains in addition to those realized through smoking cessation [39].

In summary, while SimSmoke suggests that we are unlikely to reach the HP2010 smoking goals even if the tobacco policy objectives are met as of 2004, we are projected to be much closer to those goals than without the policies. With the implementation of HP2010 policy objectives, we project a smoking rate of about $16 \%$ in 2010. Evidence from California, which has had policies in line with these goals, suggests that this projection is attainable [40]. We may be able to do somewhat better with higher taxes, especially in the states with taxes currently below the targets and through better coordinated cessation/quitline programs. In future years, it will be important to carefully track the effect of tobacco control policies on smoking rates. Policies will need to be individually and collectively considered. By closely monitoring and evaluating policies, feedback of their effectiveness might be communicated to policy makers. Simulation models such as SimSmoke provide a potentially effective tool in these efforts.

\section{Acknowledgements}

We would like to thank the Cancer Intervention and Surveillance Modeling Network (CISNET) of the he Division of Cancer Control and Population Sciences (DCCPS), National Cancer Institute (NCI) for their support under grant UO1-CA97450-02.

\section{Appendix A}

\section{SimSmoke model: mathematical appendix}

The SimSmoke model begins with the population in a baseline year first divided into the number of smokers, never smokers, and former smokers. Assuming a discrete first order Markov process, population evolves over time through birth and births and deaths, and the smoking population evolves through initiation, cessation and relapse.

\section{Demographics model}

SimSmoke is built first on a demographic model. The total population (Pop) is distinguished by time period $t$ and age 
a (and is further distinguished in the model by gender and racial ethnic group). Mortality rates $(M R)$ are distinguished by age and gender. Newborns depend on first year deaths rates and fertility rates (Fert) of females by age with equal birth rates for males and females, births through the first year (age 0 ) for each gender are:

$$
\begin{gathered}
\text { Pop }_{t, 0}=0.5 *\left(1-\text { MortRate }_{0} * \Sigma^{a}\left(\operatorname{Pop}_{t, a, 1} * \text { Fert }_{a}\right),\right. \\
\text { where } t=1, \ldots, 20 ; \quad a=14, \ldots, 49 .
\end{gathered}
$$

After the first year, the population evolves as:

$$
\operatorname{Pop}_{t, a}=\operatorname{Pop}_{t-1, a-1} *\left(1-\text { MortRate }_{a}\right) .
$$

\section{Smoking rates}

SimSmoke divides the population in the base year into (1) never smokers, (2) smokers and (3) 16 categories of ex-smokers $(n=1, \ldots, 16+)$, corresponding to years since last smoking. After the base year, individuals are classified as never smokers (designated by ns) from birth until they initiate smoking or die, according to:

$$
\begin{aligned}
\text { Neversmokers }_{t, a}= & \text { Neversmokers }_{t-1, a-1} \\
& *\left(1-\text { MortRate }_{a, \mathrm{~ns}}\right) \\
& *\left(1-\text { initiation }_{\text {rate }_{a}}\right) .
\end{aligned}
$$

Through age 24, the number of smokers (designated by $s$ ) is tracked as:

$$
\begin{aligned}
\text { Smokers }_{t, a}= & \text { Smokers }_{t-1, a-1} *\left(1-\text { MortRate }_{a, s}\right) \\
& + \text { Neversmokers }_{t-1, a-1} *\left(1-\text { MortRate }_{a, s}\right) \\
& * \text { Initiation rate }_{a} .
\end{aligned}
$$

Once a smoker (designated by $s$ ), individuals continue in that category until they quit or die or re-enter the group through relapse. After age 24, smokers are tracked as:

$$
\begin{aligned}
\text { Smokers }_{t, a}= & \text { Smokers }_{t-1, a-1} *\left(1-\text { MortRate }_{t . a, s}\right) \\
& *\left(1-\text { Cessation rate }_{a}\right) \\
& +\Sigma_{n=1}^{16} \text { Ex-smokers }_{t-1, a-1, n} \\
& *\left(1-\text { MortRate }_{t, a, n}\right) *\left(\text { Relapse rate }_{a, n}\right) .
\end{aligned}
$$

First year ex-smokers are determined by the first year cessation rate applied to surviving smokers in the previous year. Individuals who have been ex-smokers for between $n=2, \ldots, 15$, are defined as:

$$
\begin{aligned}
\text { Ex-smokers }_{t, a, n}= & \text { Ex-smokers }_{t-1, a-1, n-1} \\
& *\left(1-\text { MortRate }_{a, n}\right) \\
& *\left(1-\text { Relapse rate }_{n-1}\right) .
\end{aligned}
$$

For those who have ceased smoking for more than fifteen years, we add to the above equation the ex-smokers from the previous year who had quit for more than fifteen years and have not died or relapsed in the previous year.

\section{Policy effects}

The effect for each policy is expressed in terms of an estimated percentage change, $\mathrm{PC}$, in the smoking rate, $\mathrm{SR}$, as $\mathrm{PC}_{t}=\left(\mathrm{SR}_{t}-\mathrm{SR}_{t-1}\right) / \mathrm{SR}_{t-1}$, which is based on empirical studies and the opinion of an expert panel. For most policies, their greatest effect is generally on cessation directly through an additive effect on smoking prevalence, i.e., Smokers Sta $_{t,} *\left(1+\mathrm{PC}_{i, t, a}\right)$ for policy $i$ at time period $t$ and which may vary by age $a$. The effect is generally spread equally over the first two to three years that the policy is in effect. The percentage reduction is also applied to the initiation rate as Initiation rate ${ }_{\mathrm{a}}$ * $\left(1+\mathrm{PC}_{i, t, a}\right)$ and to the first year cessation rate as Cessation rate a $_{\mathrm{a}} *\left(1-\mathrm{PC}_{\mathrm{i}, \mathrm{t}, \mathrm{a}}\right)$ throughout the years $t$ during which the policy is in effect.

When more than one policy is in effect, the percentage reductions are multiplicatively applied, i.e., $\left(1+\mathrm{PC}_{i, t, a}\right) *\left(1+\mathrm{PC}_{j, t, a}\right)$ for policies $i$ and $j$, which implies that the relative effect is independent of other policies but the absolute effect is smaller when another policy is in effect.

\section{References}

1. National Center for Health Statistics (2001) Healthy People 2000: A final review. Hyattsville MD: Public Health Service.

2. U.S. DHHS (2000) Healthy People 2010. Atlanta: Centers for Disease Control, Office of Disease Prevention and Health Promotion.

3. U.S. DHHS (1989) Reducing the health consequences of smoking: 25 years of progress: a report of the Surgeon General. Atlanta, GA, Centers for Disease Control and Prevention, National Center for Chronic Disease Prevention and Health Promotion, Office on Smoking and Health.

4. CDC (2002) Annual smoking-attributable mortality, years of potential life lost, and economic costs-United States, 1995-1999. MMWR Morb Mortal Wkly Rep 51(14): 300-303.

5. CDC (2002) www.cdc.gov/tobacco/research_data/adults_prev/adstat3.htm and www.cdc.gov/tobacco/research_data/adults_prev/ tab_3.htm, CDC website.

6. CDC (2004) Cigarette smoking among adults - United States, 2002. MMWR Morb Mortal Wkly Rep 53(20): 427-431.

7. Mendez D, Warner KE (2000) Smoking prevalence in 2010: why the healthy people goal is unattainable. Am J Public Health 90(3): 401-403.

8. Green LW, Eriksen MP, Bailey L, Husten C (2000) Achieving the implausible in the next decade's tobacco control objectives. Am J Public Health 90(3): 337-339. 
9. Levy DT, Nikolayev N, Mumford EA (2004) A validation of the SimSmoke Simulation Model: The Role of Tobacco Control Policies in Recent Years. Calverton, MD: PIRE Working Paper.

10. Levy DT, Cummings KM, Hyland A (2000) A simulation of the effects of youth initiation policies on overall cigarette use. $A m J$ Public Health 90(8): 1311-1314.

11. Levy DT, Chaloupka F, Gitchell J, Mendez D, Warner KE (2002) The use of simulation models for the surveillance, justification and understanding of tobacco control policies. Health Care Manag Sci 5(2): 113-120.

12. U.S. DHHS (1992) Smoking and Health in the Americas: a Report of the Surgeon General, in Collaboration with the Pan American Health Organization. Atlanta, GA: Centers for Disease Control and Prevention, National Center for Chronic Disease Prevention and Health Promotion, Office on Smoking and Health.

13. U.S. DHHS (1990) The Health Benefits of Smoking Cessation: A Report of the Surgeon General. Atlanta Georgia: U.S. Department of Health and Human Services, Public Health Service, Centers for Disease Control, Office on Smoking and Health.

14. Levy DT, Friend K (2002) Examining the effects of tobacco treatment policies on smoking rates and smoking related deaths using the SimSmoke computer simulation model. Tob Control 11(1): 47-54.

15. Levy DT, Friend K (2002) A simulation model of policies directed at treating tobacco use and dependence. Med Decis Making 22(1): 6-17.

16. McWhorter WP, Boyd GM, Mattson ME (1990) Predictors of quitting smoking: the NHANES I followup experience. J Clin Epidemiol 43(12): 1399-1405.

17. Gilpin EA, Pierce JP, Farkas AJ (1997) Duration of smoking abstinence and success in quitting. J Natl Cancer Inst 89(8): 572 576.

18. National Cancer Institute (2000) State and Local Legislative Action to Reduce Tobacco Use. Bethesda MD: U.S. DHHS, National Institutes of Health, National Cancer Institute.

19. Wakefield M, Chaloupka F (2000) Effectiveness of comprehensive tobacco control programmes in reducing teenage smoking in the USA. Tob Control 9(2): 177-186.

20. Levy DT, Cummings KM, Hyland A (2000) Increasing taxes as a strategy to reduce cigarette use and deaths: results of a simulation model. Prev Med 31(3): 279-286.

21. Levy DT, Mumford EA (2004). The Healthy People 2000 and 2010 Tobacco Control Policies Objectives: A Review of the Policies Implemented in 1990-2004. Calverton MD: Pacific Insititute.

22. Levy DT, Gitchell JG, Chaloupka F (2004) The effects of tobacco control policies on smoking rates: a tobacco control scorecard. J Public Health Manag Pract 10: 338-351.

23. Levy DT, Friend K, Holder H, Carmona M (2001) Effect of policies directed at youth access to smoking: results from the SimSmoke computer simulation model. Tob Control 10(2): 108-116.

24. Farrelly M and Bray J (1998) Responses to increases in cigarette prices by race/ethnicity, income, and age groups - United States,
1976-1993. Morbidity and Mortality Weekly Report 47(29): 605609.

25. Levy DT, Friend K, Polishchuk E (2001) Effect of clean indoor air laws on smokers: the clean air module of the SimSmoke computer simulation model. Tob Control 10(4): 345351.

26. Levy DT, Friend K (2001) A computer simulation model of mass media interventions directed at tobacco use. Prev Med 32(3): 284294.

27. CDC (2004) State medicaid coverage for tobacco-dependence treatments - United States, 1994-2002. MMWR Morb Mortal Wkly Rep 53(3): 54-57.

28. McPhillips-Tangum C, Cahill A, Bocchino C, Cutler CM (2002) Addressing tobacco in managed care: results from the 2000 survey. Prevent Med Managed Care 3(3): 85-95.

29. Levy DT, Friend KB (2000) A simulation model of tobacco youth access policies. J Health Polit Policy Law 25(6): 1023-1050.

30. Levy DT, Mumford E, Pesin B (2003) Tobacco control policies, and reductions in smoking rates and smoking-related deaths: results from the SimSmoke model. Expert Review of Pharmacoeconomics and Outcomes Research 3(4): 457-468.

31. U.S. DHHS (2000) Reducing Tobacco Use: a Report of the Surgeon General. Atlanta, GA: Centers for Disease Control and Prevention, National Center for Chronic Disease Prevention and Health Promotion, Office on Smoking and Health.

32. Hopkins DP, Briss PA, Ricard CJ, et al. (2001) Reviews of evidence regarding interventions to reduce tobacco use and exposure to environmental tobacco smoke. Am J Prev Med 20 (2 Suppl): 16-66.

33. Levy D, Romano E, Mumford E (2004) Recent trends in home and work smoking bans. Tobacco control 13: 258-263.

34. Friend K, Levy D (2002) Reductions in smoking prevalence and cigarette consumption associated with mass-media campaigns. Health Educ Res 17: 1, 85-98.

35. Pierce JP, Gilpin EA (2002) Impact of over-the-counter sales on effectiveness of pharmaceutical aids for smoking cessation. JAMA 288(10): 1260-1264.

36. Thorndike AN, Biener L, Rigotti NA (2002) Effect on smoking cessation of switching nicotine replacement therapy to over-thecounter status. Am J Public Health 92(3): 437-442.

37. Jha P, Chaloupka F, eds (2000) Tobacco Control in Developing Countries. New York: Oxford University Press.

38. Hughes JR (2000) Reduced smoking: an introduction and review of the evidence. Addiction 95(Suppl 1): S3-S7.

39. Stratton K, Shetty P, Wallace R, Bondurant S (2001) Clearing the smoke: the science base for tobacco harm reduction - executive summary. Tob Control 10(2): 189-195.

40. Gilpin E A, Emery S L, Farkas A J, et al. (2003) Tobacco Control Successes in California: A focus on the Young People, Results from the California Tobacco Control Surveys, 1990-2002. La Jolla, CA: University of California, San Diego.

41. CDC (2003) Cigarette smoking among adults - United States, 2001. MMWR Morb Mortal Wkly Rep 52(40): 953-956. 